\title{
Clinical and Ultrasonographic Evaluation of Masticatory Muscles in Young Subjects with and Without Bruxism
}

\section{Bruksizmi Olan ve Olmayan Genç Bireylerde Çiğneme Kaslarının Klinik ve Ultrasonografik Olarak Değerlendirilmesi}

\author{
(1) Hakan Eren ${ }^{1}$, (1) Nilsun Bağış², (10 Başak Bıyıkoğlu³ \\ ${ }^{1}$ Ankara University Faculty of Dentistry, Department of Oral and Maxillofacial Radiology, Ankara, Turkey \\ ${ }^{2}$ Ankara University Faculty of Dentistry, Department of Periodontology, Ankara, Turkey \\ ${ }^{3}$ Altınbaş University Faculty of Dentistry, Department of Periodontology, İstanbul, Turkey
}

Keywords

Bruxism, stress, ultrasonography

Anahtar Kelimeler

Bruksizm, stres, ultrasonografi

Received/Geliş Tarihi : 27.12 .2020

Accepted/Kabul Tarihi : 14.01.2021

doi:10.4274/meandros.galenos.2021.29291

Address for Correspondence/Yazışma Adresi: Başak Bıyıkoğlu Assoc. Prof.,

Altınbaş University Faculty of Dentistry,

Department of Periodontology, İstanbul,

Turkey

Phone : +90 5333538813

E-mail : basak.biyikoglu@altinbas.edu.tr

ORCID ID: orcid.org/0000-0001-8830-9835

(c) Meandros Medical and Dental Journal, Published by Galenos Publishing House.

This is article distributed under the terms of the

Creative Commons Attribution NonCommercial 4.0

International Licence (CC BY-NC 4.0).

\begin{abstract}
Objective: This study aimed to evaluate the stress levels and alterations in temporomandibular joint (TMJ) and masticatory muscle thickness determined by ultrasonography (USG) in young individuals with and without bruxism.

Materials and Methods: A total number of 63 eligible subjects were included. In both test $(n=33)$ and control $(n=30)$ groups, Fonseca Questionnaire, Beck's Depression inventory (BDI) were used as determinants of the presence of bruxism and stress levels. Clinical examination of TMJ and USG measurements of masticatory muscle thicknesses were recorded.

Results: Age, sex distribution, and BDI scores were comparable in the test and control groups ( $p>0.05)$. The presence of pain during palpation was significantly higher in TMJ (bilateral) and in masseter, temporal muscles, and temporal tendon (unilateral) of the test group $(p<0.05)$. Masticatory muscle thicknesses, as determined by USG, were higher in the control group; however, the differences were not statistically significant ( $p>0.05$ ).

Conclusion: As opposed to pain during palpation, USG evaluation revealed no differences in masticatory muscle thicknesses in young subjects with and without bruxism. Considering the rather young study sample, these results suggest that alterations in the stomatognathic system could occur in the long term.
\end{abstract}

Öz

Amaç: Çalışmanın amacı bruksizmi olan ve olmayan genç bireylerde stres seviyeleri ile temporomandibuler eklemde (TME) ve ultrasonografik olarak belirlenen çiğneme kas kalınlıklarında meydana gelen değişikliklerin değerlendirilmesidir.

Gereç ve Yöntemler: Çalışmaya, dahil edilme kriterlerine uyan toplam 63 birey dahil edilmiştir. Test $(n=33)$ ve kontrol $(n=30)$ gruplarında bruksizm varlığı ve stres seviyeleri sırasıyla Fonseca anketi, Beck Depresyon ölçeği (BDI) ile değerlendirilmiştir. TME'nin klinik muayenesi ve ultrasonografi (USG) ile çiğneme kaslarının kalınlık ölçümleri kaydedilmiştir.

Bulgular: Test ve kontrol grupları arasında yaş, cinsiyet dağılımı ve BDI skorları açısından istatistiksel olarak anlamlı fark gözlenmemiştir ( $p>0,05)$. Palpasyonda ağrı bulgusu TME'de çift taraflı olarak, masseter kas, temporal kas ve temporal tendonda ise tek taraflı olarak test grubunda kontrol grubuna göre anlamlı derecede yüksek 
bulunmuştur ( $p<0,05)$. Çiğneme kas kalınlıklarının USG ile ölçümleri sonucunda ise kas kalınlıklarının kontrol grubunda test grubuna daha fazla olduğu, fakat bu farklılığın istatistiksel anlamlılık seviyesine ulaşmadığı gözlenmiştir $(p>0,05)$.

Sonuç: Palpasyonda ağrı bulgusunun aksine, çiğneme kas kalınlıklarının USG ile ölçümü sonucunda her iki grup arasında istatistiksel olarak anlamlı fark gözlenmemiştir. Çalışma grubunu oluşturan bireylerin genç bireyler olmaları, bruksizme bağlı olarak gelişen kas hipertrofisinin uzun dönemde gerçekleştiğini düşündürmektedir.

\section{Introduction}

Bruxism is defined as "masticatory muscle activities that occur during sleep and wakefulness". Sleep bruxism is characterized as rhythmic or nonrhythmic, whereas awake bruxism is characterized by repetitive or sustained tooth contact and/or bracing or thrusting of the mandible (1). Bruxism is considered to be a parafunctional activity conducing pathological conditions in stomatognathic system such as pain, increased tonus in masticatory muscles and limited jaw movement, and it is considered to be a risk factor effecting temporomandibular joint (TMJ), as well. $(2,3)$ Although, there are clinical studies reporting uni- or bilateral hypertrophy in masticatory muscles in subjects with long-term bruxism (3), there is conflicting data regarding the relationship between bruxism and masticatory muscle alterations (4). In a study evaluating the sleep bruxism related changes occurred in masseter and temporal muscles, it was reported that masticatory muscle functions were negatively affected, while there were no statistically significant differences in muscle thickness (5). In a recently published study, the thickness of mandibular adductor muscles in bruxism patients with and without tooth wear was evaluated by ultrasonography (USG), and it was concluded that masticatory muscle thickness was increased in the presence of bruxism (6). Among advanced imaging methods used for the examination of masticatory muscles, USG, is uncomplicated, low cost, applicable and reproducible method to analyze muscle function and thickness (79).

In 2013, a grading system is proposed for the diagnosis of bruxism. According to the grading system, possible sleep/awake bruxism is based on positive self-report, solely. Probable sleep/awake bruxism is based on positive clinical examination with or without the presence of positive self-report done, whereas, definite sleep/awake bruxism is based on a positive instrumental evaluation with or without the presence of a positive self-report and/or clinical inspection
(1). Fonseca questionnaire, which was proposed to categorize the severity of temporomandibular disorders (TMDs), is a multi-dimensional assessment tool to obtain epidemiological data. It may also be employed for the self-reported assessment of bruxism along with clinical examination for diagnostic purposes (10).

Stress is suggested to play important role on bruxism, through the mechanism of neurotransmission from brain to masticatory muscles (11). Epidemiological studies reveal a prevalence rate increase from $5 \%$ to $22 \%$ among university students in 1966 and 2002, respectively (12). In a study evaluating the relationship between perceived stress and bruxism, it was reported that university students showed higher levels of bruxism and stress levels compared to the general population and positive correlation between stress and bruxism in male students (11).

Although, TMD is considered to be commonly seen clinical consequence of bruxism, there is not sufficient evidence to support this phenomenon. In a systematic review by Manfredini and Lobezzoo (2), it was suggested that clinical studies were required in order to clarify the association between bruxism and TMD. The authors emphasized the need for studies in which, diagnosis of bruxism is based on more quantitative and specific methods in order to avoid potential bias and confounding factors interfering with the outcomes.

The hypothesis of the current study is stress related bruxism affects TMJ and masticatory muscle thickness. The aim of our study is to evaluate the stress levels and alterations in both, TMJ and masticatory muscle thickness determined by USG in dental students with and without bruxism.

\section{Materials and Methods}

The study was conducted among dental students in Ankara University, Faculty of Dentistry between March 2019 and June 2019 according to the guidelines 
of the Declaration of Helsinki (in full compliance with the ethical principles outlined in Helsinki Declaration). The study protocol was evaluated for ethical considerations and approved by the Non-Drug Clinical Trials Ethics Committee of Ankara University, Faculty of Dentistry (protocol no: 36290600/38, date: 26.09.2019). All participants were informed about the study protocol and informed consent was obtained before the initiation of the study.

Total number of 120 subjects were recruited for the study. Fonseca questionnaire was employed as a self-reported determinant of possible bruxism habit (13). Subjects with Fonseca score $>45$ was considered as bruxism patients $(n=33)$ and included in the test group. Subjects for the control group $(n=30)$ were randomly chosen among volunteer subjects who is not considered as bruxism patient according to Fonseca score. Volunteer subjects with full dentition and who signed the informed consent form were included in the study. Exclusion criteria were as follows: 1- Presence of periodontal disease, 2- presence of orthodontic anomalies which interfere with the occlusal relations, 3- being under orthodontic treatment or having it completed within the last 1 year, 4- history of maxillofacial surgery, 5 - being under antidepressant medication.

Demographic data were collected, and depression levels defined by Beck Depression inventory (BDI) was evaluated in both test and control groups (14).

Fonseca questionnaire is composed of 10 questions which evaluate the presence of pain in TMJ, head, back and during chewing function, presence of parafunctional habits, limited movement, clicking, perception of malocclusion and sensation of emotional stress (10). BDI is a questionnaire consisting of 21 questions about depression symptoms. Every question is answered by choosing one of four responses that are scored between 0 and 3 points. According to $\mathrm{BDI}$, scores ranging between 0 to 10 indicates minimal depression with no deviation from the norm. The scores between 11-16 are an indicator of mild depression. The scores from 17-20 is considered as an indicator of borderline of clinical depression and, the scores from 21 to 30 indicates moderate depression. Severe and extreme depressive disorder is indicated by the scores 31-40 and 41-63, respectively.

Clinical examination consisted of measurement of mandibular movement range, recording of TMJ sounds, and palpation of masticatory muscles and TMJ in both test and control groups. All clinical examinations and USG measurements were done by an experienced examiner (H.E). Mandibular movement range in over-jet, over-bite, left and right lateral and protrusive movements were measured in millimeters. Also, interincisal maximum mouth opening, forced mouth opening and pain free mouth opening measurements were performed. The presence TMJ sounds defined by clicking and palpation in left and right sides were recorded. The presence of pain during palpation of masseter, temporalis and lateral pterygoid muscles were recorded. The posterior mandibular, submandibular and temporal tendon sites were examined for the pain in palpation bilaterally.

Clinical evaluation was followed by USG analysis (Aloka Prosound Alpha-6, Hitachi, Tokyo, Japan) to evaluate the thickness of masticatory muscles. Bilateral linear evaluation of the thickness of masseter, temporalis and anterior portion of digastric muscles were performed by using $13-4 \mathrm{MHz}$ linear probe, while 1-15 $\mathrm{MHz}$ hockey probe was used to evaluate the thickness of lateral pterygoid muscles. The subjects were seated with their heads resting on the headrest of the chair during the examination. The masseter muscle was imaged at the level of mandibular ramus and the widest distance in the posterior, middle and anterior margins were linearly measured. The anterior horizontal band of temporal muscle was transversally imaged between upper and outer border of orbita and anterior border of hairline and widest part is measured linearly. The lateral pterygoid muscle was imaged at transversal direction intraorally. After opening the mouth, the lateral pterygoid muscle which is attached to the lateral pterygoid plate, was observed as triangular shaped muscle and the distance between inner and outer parts at maxillary posterior buccal region is defined as its thickness. Anterior portion of digastric muscle was observed bilaterally by using the probe in transvers position on the outer surface of submandibular region and thickness of the muscle was measured. The measurements for masseter muscle were done at rest and clench positions $(7,15,16)$.

\section{Statistical Analysis}

Statistical analyses were performed in SPSS (ver.24) statistics package program. Power for each 
variable (strength of test) was set at least 0.80 and a type 1 error of 0.05 for sample width. Cohen's $d$ in the calculation of effect size tested and $d$ value was calculated as -0.89 . As a result of the power analysis, minimum sample size was calculated as at least 25 subjects in each group. Thus, a sample size of at least 30 subjects for each group were included. Descriptive statistics for continuous variables were expressed as average, and standard deviation, values; categorical variables were expressed as number and percentage. Shapiro-Wilk's test was used to examine normality distributions of continuous variables. As a result, the data were found to have a normal distribution, so Independent t-test or Paired t-test (Paired) in paired comparisons was performed. Statistical significance level in calculations was taken as $5 \%(p=0.05)$.

\section{Results}

The age, gender distribution, Fonseca scores and BDI scores of the subjects are shown in Table 1. There were no statistically significant differences between test and control groups in terms of age $(p>0.05)$. The female to male ratio was 5:28 and 10:20 in test and control groups, respectively. There were no significant differences between the study groups in the female to male ratio $(p>0.05)$. Since, Fonseca scores were utilized as a determinant of bruxism, it was found to be statistically different between test and control groups $(p<0.05)$. The test group revealed higher BDI scores, whereas the difference between the study groups did not reach the level of statistical significance $(p>0.05)$.

Mandibular movement range measurements in over-jet, over-bite, left and right lateral movements, protrusion, interincisal maximum mouth opening, forced mouth opening and pain free mouth opening are shown in Table 2. There were no statistically significant differences between the test and control groups in any of parameters measured ( $p>0.05$ ).

When bilateral TMJ sounds were evaluated, the presence of both clicking and crepitation sounds were found to be statistically significantly higher in the test group compared to the control group $(p<0.05)$. There were no differences between left and right sides of TMJ in both groups (Table 3 ).

The presence of pain symptom during palpation was found to be significantly higher during the palpation of masseter muscle in the left side, temporal muscle in the right side and the temporal tendon in the right

\begin{tabular}{|l|l|l|}
\hline \multicolumn{2}{|l|}{ Table 1. Comparison of the mean values of demographic data, Fonseca score and Beck's Depression inventory } \\
\hline Age range (years) & Test group ( $\mathbf{n}=\mathbf{3 3})$ & Control group ( $\mathbf{n}=\mathbf{3 0}$ ) \\
\hline Age (years) (mean \pm standard deviation) & $21-24$ & $20-25$ \\
\hline Gender (female/male) & $21.4 \pm 0.92$ & $21.2 \pm 1.15$ \\
\hline Fonseca score (mean \pm standard deviation) & $5 / 28$ & $10 / 20$ \\
\hline BDI (mean \pm standard deviation) & $59.39 \pm 12.73 *$ & $22.5 \pm 13.30$ \\
\hline *Statistically significant difference compared to control group ( $p<0.05)$, BDI: Beck Depression inventory \\
\hline
\end{tabular}

Table 2. Comparison of the mean value of mandibular movement range

\begin{tabular}{|l|l|l|}
\hline \multirow{2}{*}{ Over-jet $(\mathrm{mm})$} & Test group (n=33) & Control group (n=30) \\
\cline { 2 - 3 } & Mean \pm SD & Mean \pm SD \\
\hline Over-bite $(\mathrm{mm})$ & $2.64 \pm 1.40$ & $2.42 \pm 1.08$ \\
\hline Right lateral $(\mathrm{mm})$ & $2.98 \pm 1.61$ & $3.57 \pm 1.71$ \\
\hline Left lateral $(\mathrm{mm})$ & $8.33 \pm 2.86$ & $7.87 \pm 2.78$ \\
\hline Protrusion $(\mathrm{mm})$ & $8.06 \pm 2.42$ & $8.07 \pm 3.18$ \\
\hline Max mouth opening $(\mathrm{mm})$ & $7.09 \pm 4.63$ & $6.53 \pm 2.70$ \\
\hline Forced mouth opening $(\mathrm{mm})$ & $46.33 \pm 5.89$ & $46.7 \pm 35.52$ \\
\hline Pain free mouth opening $(\mathrm{mm})$ & $48.88 \pm 5.27$ & $49.20 \pm 6.18$ \\
\hline SD: standard deviation, no significant differences were found $(\mathrm{p}>0.05)$ & $38.50 \pm 4.99$ \\
\hline
\end{tabular}


side $(p<0.05)$. The presence of pain during the palpation of TMJ was found to be significantly higher bilaterally in the test group compared to control group $(p<0.05)$. The test group presented higher percentages of positive pain symptom compared to control group in all examined sites, whereas statistical significance was observed only, in the aforementioned muscles and sides (Table 4). Pain in the masticatory muscles and TMJ due to alterations in the stomatognathic system is of importance for its negative impact on life quality (10).
The bilateral USG measurements has shown that the thickness of masseter muscle was both in rest and clenching positions was bilaterally higher in the control group compared to the test group (Figure 1), however the difference was not statistically significant ( $p>0.05)$. The thickness of temporal, lateral digastric and lateral pterygoid muscles were similar in both groups according to the bilateral USG measurements ( $>0.05$ ) (Table 5, Figure 2).

\begin{tabular}{|c|c|c|c|c|}
\hline & \multicolumn{2}{|c|}{ Test group (n=33) } & \multicolumn{2}{|c|}{ Control group $(n=30)$} \\
\hline & Left & Right & Left & Right \\
\hline Clicking & $72.72 \% *$ & $69.69 \% *$ & $43.33 \%$ & $33.33 \%$ \\
\hline Crepitation & $27.27 \%$ & $27.27 \%$ & $3.33 \%$ & $3.33 \%$ \\
\hline
\end{tabular}

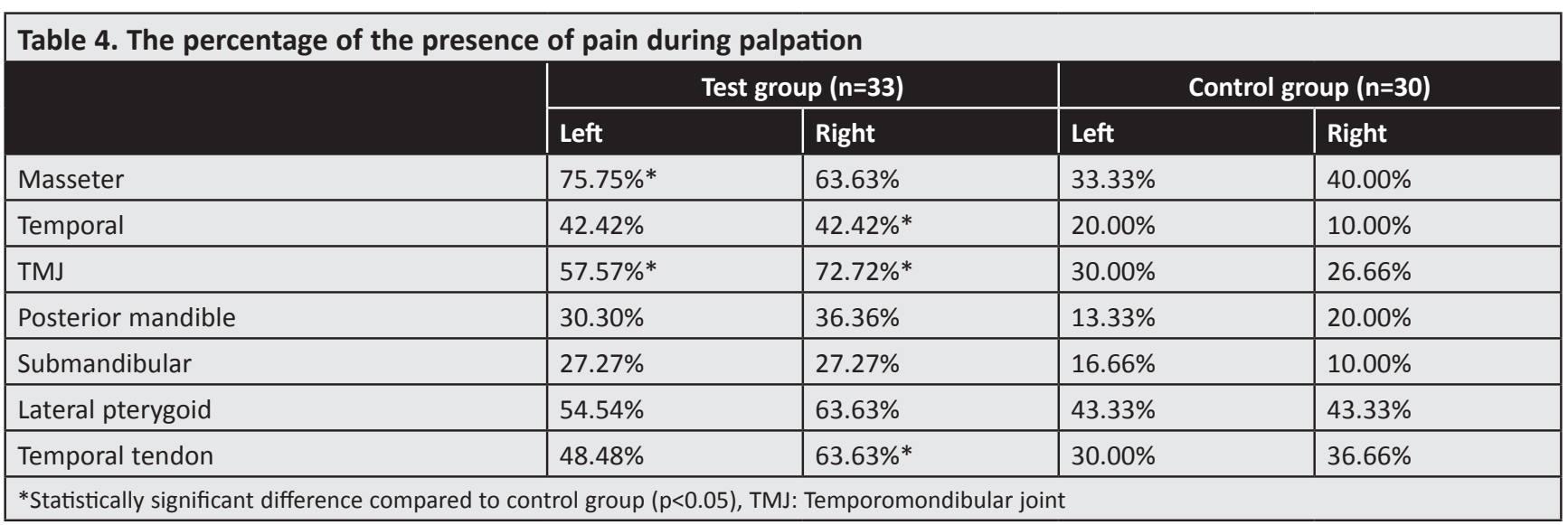

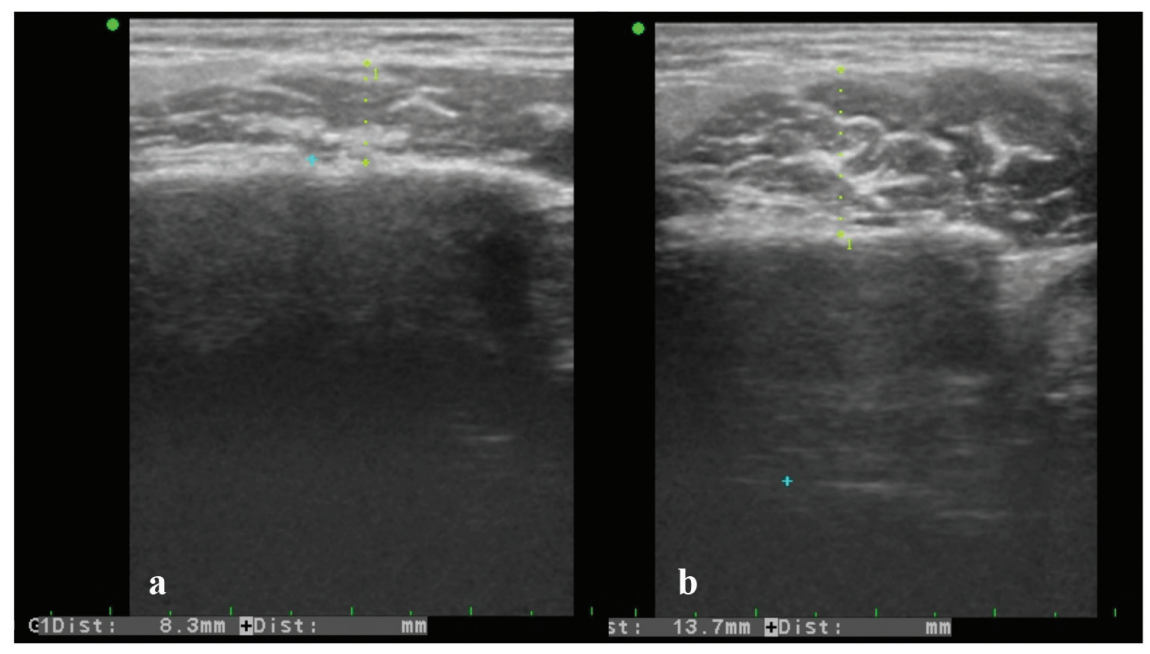

Figure 1. Ultrasonographic appearance of masseter muscle in rest (a) and clenching (b) positions. Approximately 5,4 mm increase in thickness of masseter muscle is clearly seen in clenching position 


\begin{tabular}{|l|l|l|l|l|}
\hline \multirow{2}{*}{ Table 5. The mean value of ultrasonography measurements of masticatory muscle thicknesses } \\
\cline { 2 - 5 } & \multicolumn{2}{|c|}{ Test group ( $\mathbf{n}=33$ ) } & \multicolumn{3}{c|}{ Control group ( $\mathbf{n}=30$ ) } \\
\cline { 2 - 5 } & \multicolumn{2}{|c|}{ Mean SD } & \multicolumn{3}{c}{ Mean SD } \\
\cline { 2 - 5 } & Left & Right & $7.97 \pm 1.79$ & $7.91 \pm 1.77$ \\
\hline Masseter (at rest) & $7.10 \pm 1.20$ & $7.6 \pm 1.25$ & $12.89 \pm 2.59$ & $12.79 \pm 2.55$ \\
\hline Masseter (clenching) & $11.67 \pm 2.03$ & $11.81 \pm 1.93$ & $10.33 \pm 1.68$ & $10.98 \pm 1.90$ \\
\hline Temporal & $10.23 \pm 1.88$ & $10.54 \pm 1.98$ & $5.95 \pm 1.46$ & $6.61 \pm 1.48$ \\
\hline Lateral digastric & $5.52 \pm 0.95$ & $5.85 \pm 0.99$ & $5.52 \pm 0.83$ & $5.45 \pm 0.64$ \\
\hline Lateral pterygoid & $5.41 \pm 0.80$ & $5.60 \pm 0.55$ & & \\
\hline SD: Standard deviation, no significant differences were found $(\mathrm{p}>0.05)$ & & & \\
\hline
\end{tabular}

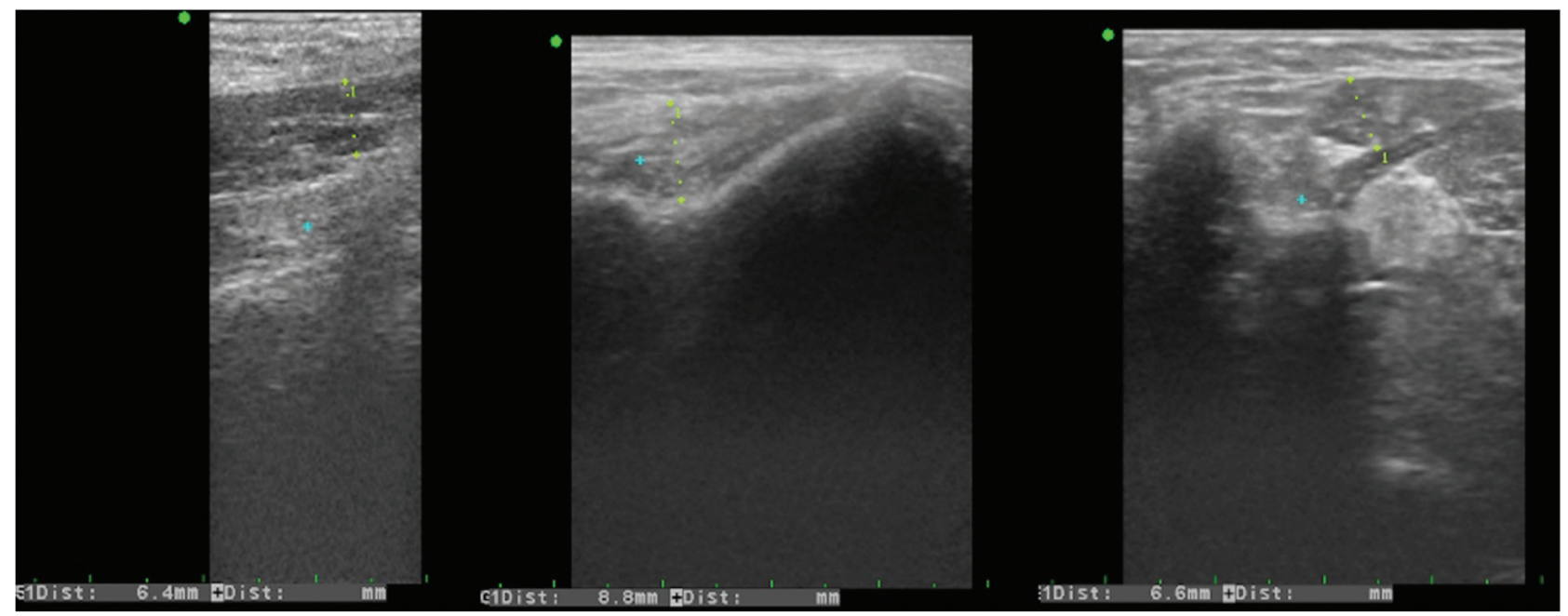

Figure 2. Ultrasonographic images of lateral pterygoid (a), temporal (b) and anterior portion of digastric (c) muscles with thickness measurements

\section{Discussion}

In this cross-sectional study, we hypothesized that stress related bruxism affects TMJ and masticatory muscle thickness and the aim of our study is to evaluate the stress levels and clinical alterations in TMJ and masticatory muscles and also the effect of bruxism on masticatory muscle thickness determined by USG in dental students with or without bruxism. The Fonseca's questionnaire was used as a self-reported determinant of bruxism (10). The questionnaire is composed of 10 questions that are answered with "yes", "no" or "sometimes" and each question should be answered by only one answer. The lack of time limitation to complete the questionnaire prevents induced answers by the subjects. Fonseca scores between 0-15 is related to no TMD, the scores from 20 to 40 is related to mild TMD, from 45 to 65 is related to moderate TMD and the scores from 70 to 100 is considered as sign of severe TMD. In our study, among 120 dental students who have completed the Fonseca's questionnaire, total number of 33 subjects with the Fonseca score $>45$ are considered as bruxism patients. In a study by Nomura et al. (17), Fonseca's questionnaire was used to evaluate 218 dental students and $35.78 \%$ of the subjects were found to have mild levels of TMD, $11.93 \%$ of the subjects were found to have moderate levels of TMD and only $5.5 \%$ of the participants had severe TMD. In another study conducted among dental students $(n=409)$, the severity of TMD was mild in $38.6 \%$ of the subjects, moderate in $13.4 \%$ of the subjects and severe in $4.4 \%$ of the subjects (13). In the current study, $20 \%$ of the all subjects included had moderate levels of TMD and $7.5 \%$ of the subjects had severe levels of TMD. The 
percentages of subjects with moderate and severe TMD is found to be comparable with the similar studies which were conducted in dental students. Since, the test group was constituted of subjects with scores higher than 45 , the difference of the Fonseca score between the test and control groups were statistically significant, as expected. The employment of questionnaires designed to assess bruxism are considered among non-instrumental approaches and self-reported assessment of bruxism is still the primary tool in the assessment of bruxism for both clinical and research purposes. The possible limitation of self-report is the complex relationship of bruxism and psychological factors (1). In the current study, the difference between the stress levels of test and control groups were not statistically significant, therefore we may assume that the subjects' stress levels did not interfere with their perception of bruxism.

The BDI scores were $12.8 \pm 7.25$ and $10.80 \pm 7.40$ in test and control groups, respectively. Although, the stress levels defined by BDI is higher in the test group compared to the control group, the difference was not statistically significant. The relationship between stress and bruxism has been studied extensively, and there are many studies indicating a positive correlation in between (18). In a study evaluating the behavior profile of children with bruxism, it was suggested that potential emotional problems could be risk factors of bruxism in children (19). In another study by SerraNegra et al. (20), the relationship between stress levels, personality traits, and sleep bruxism in children were evaluated and it was reported that stress high levels were effective on sleep bruxism development in children. There are also some studies reporting partial relationship between stress and bruxism. Cavallo et al. (11), evaluated the prevalence of awake and sleep bruxism and concluded that there was a positive correlation between perceived stress and bruxism only in male gender and they also reported that university students had higher stress levels compared to general population. In a study examining the job associated psychological stress and sleep bruxism reported weak relationship between stress and bruxism in men (21). Ohlmann et al. (22), conducted a study in order to assess the association between sleep quality, the presence of chronic stress and sleep bruxism and have shown no significant relationship.
Likewise, our results did not reveal any differences in the stress levels of subjects with or without bruxism.

Bruxism causes some alterations in the stomatognathic system structure. As a result, there may be pain in the palpation of TMJ and the presence of sounds from the joint. The lack of lateral pterygoid muscle coordination, the change in capitulum mandibula, vertical dimension loss and mandibular displacement may be the reason for the clinical symptoms (23). In our study, the percentage of the presence of TMJ sounds as clicking and crepitation were significantly higher in the test group compared to the control group, whereas there were no differences between the left and right sides in both groups. In a study evaluating the self-reported bruxism and associated factors, the prevalence of subjects reporting the presence of oro-facial pain, neck pain and joint sounds were similar (24). Although, the results of aforementioned study are based on selfreported data rather than clinical examination, the similarity in the prevalence of TMJ sound and TMD supports association between bruxism and joint sound.

Pain in the masticatory muscles and TMJ due to alterations in the stomatognathic system is of importance for its negative impact on life quality (10). There are studies supporting the association of bruxism and pain symptom. In a study by Huang et al. (25), an association between myofascial pain and self-reported bruxism with an odds ratio of $4: 8$ was reported. In another study evaluating the perceived orofacial pain associated to reported bruxism, positive association was demonstrated (26). Similarly, in our study subjects with bruxism revealed to have higher percentages of positive pain in palpation results compared to the control group, however statistically significance was observed in the left masseter muscle, in the right temporal muscle, in the right temporal tendon and in the both sides of TMJ. However, it should be kept on mind that the mechanisms of pain and bruxism association is complex and data in the current literature should be interpreted carefully, since most of data presented are obtained from studies using self-reported measures of bruxism.

In the current study, USG was used to determine the masticatory muscle thicknesses. USG is an accurate, uncomplicated and affordable diagnostic method used to evaluate the thickness of the head 
and neck muscles (27). Results of our study did not reveal statistically significant difference in the thicknesses of any masticatory muscle measured in young patients with and without bruxism. However, thickness of masseter muscle was higher in the control group in both sides at rest and clenching while the thicknesses of temporalis, lateral digastric and lateral pterygoid muscles were similar in both of the study groups. It has been suggested that in subjects with bruxism increased forces on masticatory muscles may result with hypertrophy (28). In their study, Mäntyvaara et al. (29) compared the occlusal forces in bruxism patients and healthy controls and reported higher occlusal forces in the test group. Goller Bulut et al. (6), performed the USG evaluation of jaw elevator muscles in bruxism patients with and without tooth wear and they concluded that the occlusal forces, tooth wear and the thickness of masticatory muscles were increased in bruxism patients. On the contrary, Adisen et al. (4) compared the masticatory muscle volumes determined by magnetic resonance images and occlusal force distributions in patients with bruxism and healthy controls. The authors concluded that masticatory muscle hypertrophy was not a sign of sleep bruxism in young patients. As in our study, Palinkas et al. (5), employed USG in order to compare the muscle thickness in patients with and without sleep bruxism. The authors reported that there were no statistically significant differences between the study groups which is similar to our study. We assume that rather young population included in our study is accountable for the lack of significant difference between the study groups, as it may take longer period for the dimensional alterations in the masticatory muscles to occur. In our study, occlusal forces were not evaluated, therefore it is not possible to make an interpretation about its possible role on the insignificant differences in the muscle thickness.

\section{Conclusion}

In dental students with and without bruxism, there were no differences between the stress levels and masticatory muscle thicknesses between the test and control groups. However, differences in pain symptom during palpation of TMJ, masseter and temporal muscle may suggest that alterations in stomatognathic system occur in long term. There is need for further studies in larger sample size and different age groups.

\section{Ethics}

Ethics Committee Approval: The study was conducted among dental students in Ankara University, Faculty of Dentistry between March 2019 and June 2019 according to the guidelines of the Declaration of Helsinki (in full compliance with the ethical principles outlined in Helsinki Declaration). The study protocol was evaluated for ethical considerations and approved by the Non-Drug Clinical Trials Ethics Committee of Ankara University, Faculty of Dentistry (protocol no: 36290600/38, date: 26.09.2019).

Informed Consent: All participants were informed about the study protocol and informed consent was obtained before the initiation of the study.

Peer-review: Externally and internally peerreviewed.

\section{Authorship Contributions}

Concept: H.E., N.B., B.B., Design: H.E., Supervision: H.E., Data Collection or Processing: H.E., N.B., Analysis or Interpretation: H.E., N.B., B.B., Literature Search: H.E., N.B., B.B., Critical Review: H.E., N.B., B.B., Writing: B.B.

Conflict of Interest: No conflict of interest was declared by the authors.

Financial Disclosure: The authors declared that this study received no financial support.

\section{References}

1. Lobbezoo F, Ahlberg J, Raphael KG, Wetselaar P, Glaros AG, Kato $\mathrm{T}$, et al. International consensus on the assessment of bruxism: Report of a work in progress. J Oral Rehabil 2018; 45: 837-44.

2. Manfredini D, Lobbezoo F. Relationship between bruxism and temporomandibular disorders: a systematic review of literature from 1998 to 2008. Oral Surg Oral Med Oral Pathol Oral Radiol Endod 2010; 109: e26-50.

3. Camparis CM, Siqueira J. Sleep bruxism: clinical aspects and characteristics in patients with and without chronic orofacial pain. Oral Surg Oral Med Oral Pathol Oral Radiol Endod 2006; 101: 188-93.

4. Adisen MZ, Okkesim A, Misirlioglu M, Yilmaz S. Does sleep bruxism affect masticatory muscles volume and occlusal force distribution in young subjects? A preliminary study. Cranio 2019; 37: 278-84.

5. Palinkas M, Bataglion C, de Luca Canto G, Machado Camolezi N, Theodoro GT, et al. Impact of sleep bruxism on masseter and temporalis muscles and bite force. Cranio 2016 ;34: 309-15.

6. Goller Bulut D, Avci F, Özcan G. Ultrasonographic evaluation of jaw elevator muscles in young adults with bruxism and with and without attrition-type tooth wear: A pilot study. Cranio 2020; 38 : 248-55. 
7. Raadsheer MC, Kiliaridis S, Van Eijden TM, Van Ginkel FC, PrahlAndersen B. Masseter muscle thickness in growing individuals and its relation to facial morphology. Arch Oral Biol 1996; 41: 323-32.

8. Bakke M, Tuxen A, Vilmann P, Jensen BR, Vilmann A, Toft M. Ultrasound image of human masseter muscle related to bite force, electromyography, facial morphology, and occlusal factors. Scand J Dent Res 1992 100: 164-71.

9. Raadsheer MC, van Eijden TM, van Ginkel FC, Prahl-Andersen B. Contribution of jaw muscle size and craniofacial morphology to human bite force magnitude. J Dent Res 1999; 78: 31-42.

10. Karaman A, Kutalmış Buyuk S. Evaluation of temporomandibular disorder symptoms and oral health-related quality of life in adolescent orthodontic patients with different dental malocclusions. Cranio 2019: 1-9.

11. Cavallo P, Carpinelli L, Savarese G. Perceived stress and bruxism in university students. BMC Res Notes 2016; 9: 514.

12. Granada S, Hicks RA. Changes in self-reported incidence of nocturnal bruxism in college students: 1966-2002. Percept Mot Skills 2003; 97: 777-8.

13. Ayalı A, Ramoglu S. Assesment of prevalence and severity of temporomandibular disorders in North Cyprus dentistry students. J Dent Fac Atatürk Univ 2014; 24: 367-72.

14. Smardz J, Martynowicz H, Wojakowska A, Michalek-Zrabkowska M, Mazur G, Wieckiewicz M. Correlation between Sleep Bruxism, Stress, and Depression-A Polysomnographic Study. J Clin Med 2019; 8: 1344.

15. Bakke $M$, Tuxen A, Vilmann $P$, Jensen BR, Vilmann A, Toft $M$. Ultrasound image of human masseter muscle related to bite force, electro- myography, facial morphology, and occlusal factors. Scand J Dent Res 1992; 100: 164-71.

16. Chen YJ, Chang PH, Chang KV, Wu WT, Özçakar L. Ultrasound Guided Injection for Medial and Lateral Pterygoid Muscles: A Novel Treatment for Orofacial Pain. Med Ultrason 2018; 1: 1156.

17. Nomura K, Vitti M, Oliveira AS, Chaves TC, Semprini M, Siéssere $S$, et al. Use of the Fonseca's questionnaire to assess the prevalence and severity of temporomandibular disorders in Brazilian dental undergraduates. Braz Dent J 2007; 18: 163-7.

18. Smardz J, Martynowicz H, Wojakowska A, Michalek-Zrabkowska M, Mazur G, Wieckiewicz M. Correlation between Sleep Bruxism,
Stress, and Depression-A Polysomnographic Study. J Clin Med 2019; 8: 1344.

19. Ferreira-Bacci Ado V, Cardoso CL, Díaz-Serrano KV. Behavioral problems and emotional stress in children with bruxism. Braz Dent J 2012; 23: 246-51.

20. Serra-Negra JM, Paiva SM, Flores-Mendoza CE, Ramos-Jorge ML, Pordeus IA. Association among stress, personality traits, and sleep bruxism in children. Pediatr Dent 2012; 34: e30-4.

21. Nakata A, Takahashi M, Ikeda T, Hojou M, Araki S. Perceived psychosocial job stress and sleep bruxism among male and female workers. Community Dent Oral Epidemiol 2008; 36: 201-9.

22. Ohlmann B, Bömicke W, Habibi Y, Rammelsberg P, Schmitter M. Are there associations between sleep bruxism, chronic stress, and sleep quality? J Dent 2018; 74: 101-6.

23. Alóe F. Sleep Bruxism Treatment. Sleep Science 2009: 2; 4-52.

24. Emodi Perlman A, Lobbezoo F, Zar A, Friedman Rubin P, van Selms MK, Winocur E. Self-Reported bruxism and associated factors in Israeli adolescents. J Oral Rehabil 2016; 43: 443-50.

25. Huang GJ, LeResche L, Critchlow CW, Martin MD, Drangsholt MT. Risk factors for diagnostic subgroups of painful temporomandibular disorders (TMD). J Dent Res 2002; 81: 284-8.

26. Ahlberg K, Ahlberg J, Könönen $M$, Alakuijala A, Partinen $M$, Savolainen A. Perceived orofacial pain and its associations with reported bruxism and insomnia symptoms in media personnel with or without irregular shift work. Acta Odontol Scand 2005; 63: 213-7.

27. Kant P, Bhowate RR, Sharda N. Assessment of cross-sectional thickness and activity of masseter, anterior temporalis and orbicularis oris muscles in oral submucous fibrosis patients and healthy controls: an ultrasonography and electromyography study. Dentomaxillofac Radiol 2014; 43: 20130016.

28. Gibbs CH, Mahan PE, Mauderli A, Lundeen HC, Walsh EK. Limits of human bite strength. J Prosthet Dent 1986; 56: 226-9.

29. Mäntyvaara J, Sjöholm $T$, Kirjavainen $T$, Waltimo A, livonen $M$, Kemppainen $\mathrm{P}$, et al. Altered control of submaximal bite force during bruxism in humans. Eur J Appl Physiol Occup Physiol 1999; 79: 325-30. 